\title{
ANALISIS PERUBAHAN KEKERASAN YANG TERJADI PADA CINCIN TORAK AKIBAT PERUBAHAN JARAK TEMPUH PADA MOTOR YAMAHA MIO SOUL GT
}

\author{
Yano Hurung Anoi ${ }^{*}$,Alfian Bagus Eka Putra ${ }^{2}$ \\ Sekolah Tinggi Teknologi Industri (STTI) Bontang \\ Jl.Brigjend Katamso Nomor 40, Bontang,75313 \\ Email :yanodayak@yahoo.com alfianbagus@gmail.com
}

\begin{abstract}
ABSTRAK
Pada motor bakar sistem pembakar 4 langkah terdapat tiga buah cincin torak yaitu duan cincin torak kompresi dan satu cincin torak pengatur pelumasan. Cincin torak kompresi berfungsi untuk menjaga tekanan pembakaran, sedangkan cincin torak pengatur pelumasan berfungsi untuk melumasi ruang bakar selama proses perubahan energi berjalan sehingga torak akan berjalan bolak-balik didalam ruang bakar dengan lancar.

Kerusakan yang terjadi pada cincin torak dapat berupa cincin torak patah, atau cincin torak tergores atau aus. Hal-hal tesebut dapat menurunkan kwalitas proses perpindahan energi. Cincin torak patah karena cincin terlalu getas. Getaran yang terjadi pada torak saat terjadi kerja pembakaran pada beban penuh memperbesar kemungkinan proses patah pada cincin torak. Kegetasan cincin torak sangat dipengaruhi oleh bahan yang dipakai. Untuk mengatasi hal tersebut dibutuhkan bahan keras tapi tidak kaku.
\end{abstract}

Kata Kunci : Kekerasan, jarak tempuh,Pengujian Vicker

\begin{abstract}
In a four stroke combustion engine, there are three piston rings, namely two compression piston rings and one lubrication control piston ring. The piston compression ring serves to maintain the combustion pressure, while the piston ring lubrication regulator functions to lubricate the combustion chamber during the energy change process so that the piston will run back and forth in the combustion chamber smoothly.

Damage that occurs to the piston ring can be in the form of a broken piston ring, or a scratched or worn piston ring. These things can reduce the quality of the energy transfer process. The piston ring is broken because the ring is too brittle. Vibration that occurs in the piston when combustion occurs at full load increases the possibility of a fracture process in the piston ring. The brittleness of the piston ring is strongly influenced by the material used. To overcome this, a hard but not stiff material is needed.
\end{abstract}

Keywords: Hardness, mileage, Vicker test

\section{PENDAHULUAN}

Cincin torak merupakan suatu bagian yang sangat penting pada sistem pembakaran motor bakar. Cincin torak berfungsi sebagai perapat pada torak sehingga proses pembakaran dapat berjalan dengan sempurna, terutama pada tekanan pembakaran ruang bakar.

Pada motor bakar sistem pembakar 4 langkah terdapat tiga buah cincin torak yaitu duan cincin torak kompresi dan satu cincin 
torak pengatur pelumasan. Cincin torak kompresi berfungsi untuk menjaga tekanan pembakaran, sedangkan cincin torak pengatur pelumasan berfungsi untuk melumasi ruang bakar selama proses perubahan energi berjalan sehingga torak akan berjalan bolak-balik didalam ruang bakar dengan lancar.

Kerusakan yang terjadi pada cincin torak dapat berupa cincin torak patah, atau cincin torak tergores atau aus. Hal-hal tesebut dapat menurunkan kwalitas proses perpindahan energi. Cincin torak patah karena cincin terlalu getas. Getaran yang terjadi pada torak saat terjadi kerja pembakaran pada beban penuh memperbesar kemungkinan proses patah pada cincin torak. Kegetasan cincin torak sangat dipengaruhi oleh bahan yang dipakai. Untuk mengatasi hal tersebut dibutuhkan bahan keras tapi tidak kaku.

Cincin torak yang tergores dapat menyebabkan kebocoran pada ruang bakar, goresan disebabkan oleh adanya kotoran yang terdapat pada ruang bakar, akibat pembakaran atau kotoran-kotoran yang terbawa baik dari bahan bakar atau minyak pelumas.

Kekerasan suatu material harus diketahui khususnya untuk material yang dalam penggunaanya akan mengalami pergesekan (frictional force) dan deformasi plastis. Deformasi plastis sendiri suatu keadaan dari suatu material ketika material tersebut diberikan gaya maka struktur mikro dari material tersebut sudah tidak bisa kembali ke bentuk asal artinya material tersebut tidak dapat kembali ke bentuknya semula. Lebih ringkasnya kekerasan didefinisikan sebagai kemampuan suatu material untuk menahan beban identasi atau penetrasi (penekanan). Uji kekerasan adalah pengujian yang paling efektif untuk menguji kekerasan dari suatu material, karena dengan pengujian ini kita dapat dengan mudah mengetahui gambaran sifat mekanis suatu material. Meskipun pengukuran hanya dilakukan pada suatu titik, atau daerah tertentu saja, nilai kekerasan cukup valid untuk menyatakan kekuatan suatu material. Dengan melakukan uji keras, material dapat dengan mudah di golongkan sebagai material ulet atau getas.

\section{Tinjauan Teori}

Pada saat mesin dalam keadaan kerja atau beroperasi, cincin torak akan menekan ruang bakar. Besarnya tekanan akan mempengaruhi besarnya kecepatan maximum langkah piston. Besarnya tekanan pada cincin torak dipengaruhi oleh besarnya celah dan koefisien muai bahan. Bila celah terlalu longgar tekanan ruang bakar dapat bocor. Tetapi apabila tekanan terlalu kuat maka akan dapat membuat cacat pada cincin torak atau juga dapat menyebabkan cincin torak menjadi patah. Tekanan pada cincin torak akan bertambah besar bila angka muai silinder lebih besar dari angka muai cincin torak dan dengan naiknya suhu pada ruang bakar.

Metode pengujian kekerasan Vickers dilaksanakan dengan cara menekan benda uji atau spesimen dengan indentor intan yang berbentuk piramida dengan alas segi empat dan besar sudut dari permukaan-permukaan yang berhadapan $136^{\circ}$. Penekanan oleh indentor akan menghasilkan suatu jejak atau lekukan pada permukaan benda uji.

Dikenal juga sebagai Diamond Pyramid Hardness test (DPH). Uji kekerasan vickers menggunakan indentor piramida intan, besar sudut antar permukaan piramida intan yang saling berhadapan adalah 136 derajat . Ada dua rentang kekuatan yang berbeda, yaitu micro $(10 \mathrm{~g}-1000 \mathrm{~g})$ dan macro $(1 \mathrm{~kg}-100 \mathrm{~kg})$.

Rumus Pengujian Vickers :

$$
\begin{array}{ll}
V H N=\frac{2 F \operatorname{Sin}^{\theta} 2}{D^{2}}=\frac{1,8554 F}{D^{2}} \\
\text { VHN } \quad=\text { Angka kekerasan Vickers } \\
\mathrm{F} & =\text { Beban }(\mathrm{kgf}) \\
\mathrm{D} & =\text { diagonal }(\mathrm{mm})
\end{array}
$$

\section{METODE PENELITIAN}

Bahan yang digunakan dalam penelitian ini adalah :

1. Cincin torak (piston ring) kendaraan roda dua 4 langkah 125 cc Yamaha Mio Soul GT dalam keadaan baru (belum dipakai).

2. Cincin torak (piston ring) kendaraan roda dua 4 langkah 125 cc Yamaha Mio Soul GT setelah dipakai (bekas) dengan jarak tempuh yang telah diketahui (400 km, 800 km, 20.000 km, 40.000 km). 


\section{Posisi Penetrasi}

Pengukuran kekerasan pada cincin torak dilakukan pada lima titik / tempat pada cincin torak dengan pembagian seperti pada gambar di bawah ini. Pengukuran kekerasan ini juga dilakukan pada sisi atas dan bawah dari cincin torak.
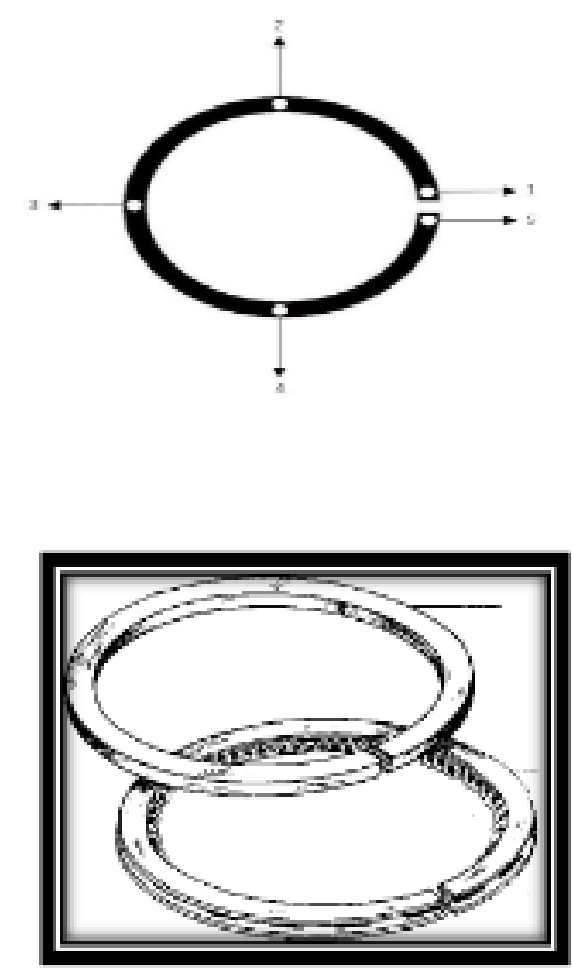

Gambar 1 Posisi Penetrasi
Diagram Alir Penelitan

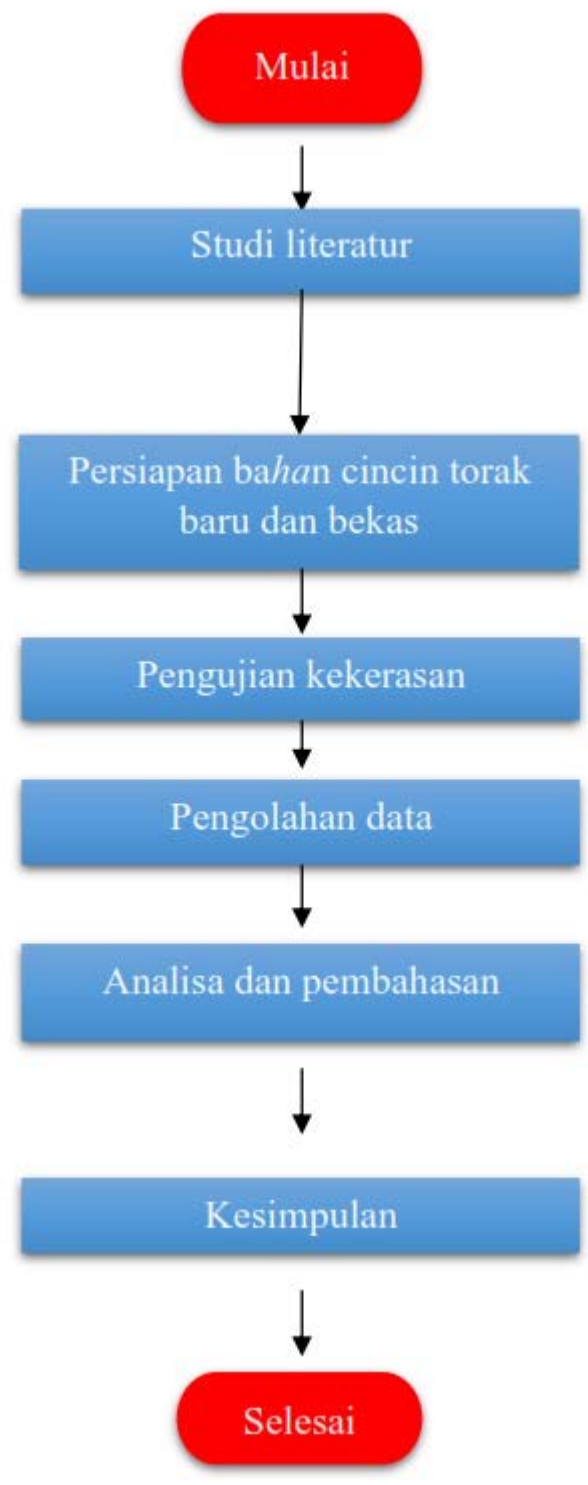

Gambar 2 diagram alir penelitian

terdiri dari :

a) 5 buah spesimen dari cincin torak kompresi I dengan jarak tempuh $0 \mathrm{~km}$, $400 \mathrm{~km}, 800 \mathrm{~km}, 20.000 \mathrm{~km}, 40.000$ $\mathrm{km}$.

b) 5 buah spesimen dari cincin torak kompresi II dengan jarak tempuh $0 \mathrm{~km}$, $400 \mathrm{~km}, 800 \mathrm{~km}, 20.000 \mathrm{~km}, 40.000$ $\mathrm{km}$.

c) 5 buah spesimen dari cincin torak pengatur pelumasan dengan jarak tempuh $0 \mathrm{~km}, 400 \mathrm{~km}, 800 \mathrm{~km}, 20.000$ km, $40.000 \mathrm{~km}$. 
HASIL DAN PEMBAHASAN

Contoh hasil pengujian cincin torak kompresi I

\begin{tabular}{|c|c|c|c|}
\hline \multirow{2}{*}{ No } & \multirow{2}{*}{ Posisi Penetrasi } & \multicolumn{2}{c|}{ Cincin Torak Kompresi I } \\
\cline { 3 - 4 } & & Atas & Bawah \\
\hline $\mathbf{1}$ & 1 & 306 & 305 \\
\hline $\mathbf{2}$ & 2 & 310 & 308 \\
\hline $\mathbf{3}$ & 3 & 312 & 310 \\
\hline $\mathbf{4}$ & 4 & 307 & 307 \\
\hline $\mathbf{5}$ & $\mathbf{5}$ & 302 & 302 \\
\hline
\end{tabular}

a) Bagian atas :

\& Kekerasan rata-rata

$\bar{x}=\sum \frac{x i}{n}=\frac{1537}{5}=307,4 \mathrm{VHN}$

Standart deviasi

$\bar{\delta}=\sum \frac{(x i-x)^{2}}{n-1}$

$\frac{\sqrt{(306-307,4)^{2}+(310-307,4)^{2}+(312-307,4)^{2}-(307-307,4)^{2}+(302-307,4)^{2}}}{5-1}$

$=\frac{\sqrt{(-1,4)^{2}+(2,6)^{2}+(4,6)^{2}+(-0,4)^{2}+(-5,4)^{2}}}{4}$

$=\frac{\sqrt{1,96+6,76+21,16+0,16+29,16}}{4}$

$=\frac{\sqrt{59,2}}{4}=\sqrt{14,8}=3,84$

* Standart deviasi rata-rata

$\bar{\delta}=\frac{\delta}{\sqrt{n}}=\frac{3,84}{\sqrt{5}}=1,71$

a) Bagian bawah :

Kekerasan rata-rata

$\bar{x}=\sum \frac{x i}{n}=\frac{1532}{5}=306,4 \mathrm{VHN}$

Standart deviasi

$\bar{\delta}=\sum \frac{(x i-x)^{2}}{n-1}$

$=$

$\frac{\sqrt{(305-306,4)^{2}+(308-306,4)^{2}+(310-306,4)^{2}-(307-306,4)^{2}+(302-306,4)^{2}}}{5-1}$

$=\frac{\sqrt{(-1,4)^{2}+(1,6)^{2}+(3,6)^{2}+(0,6)^{2}+(-4,4)^{2}}}{4}$

$=\frac{\sqrt{1,96+2,56+12,96+0,36+19,36}}{4}$

$=\frac{\sqrt{37,2}}{4}=\sqrt{9,3}=3,04$

Standart deviasi rata-rata

$$
\bar{\delta}=\frac{\delta}{\sqrt{n}}=\frac{3,04}{\sqrt{5}}=1,35
$$

$>$ Derajat bebas $(\mathrm{db})=\mathrm{n}-\mathrm{I}=5-1=4$

$>\alpha=5 \%$, maka,

$$
\mathrm{t}(\alpha / 2, \mathrm{db})=\mathrm{t}(0,025,4)=2,776
$$

Interval penduga rata-rata kekerasan :

Bagian atas :

$$
\bar{x}-\mathrm{t}(\alpha / 2, \mathrm{db})<\mathrm{x}<\bar{x}+\mathrm{t}(\alpha / 2, \mathrm{db}) \bar{\delta}
$$

$307,4-(2,776) 1,71<x<307,4+(2,776) 1,71$

$$
302,6 \mathrm{VHN}<\mathrm{x}<312,1 \mathrm{VHN}
$$

Bagian bawah :

$$
\bar{x}-\mathrm{t}(\alpha / 2, \mathrm{db})<\mathrm{x}<\bar{x}+\mathrm{t}(\alpha / 2, \mathrm{db}) \bar{\delta}
$$

$306,4-(2,776) 1,35<x<306,4+(2,776) 1,35$

$$
302,7 \text { VHN }<x<310,2 \text { VHN }
$$

Jadi dari hasil perhitungan data diatas dapat disimpulkan yaitu, kekerasan cincin torak kompresi I dengan jarak $0 \mathrm{~km}$ (baru) pada bagian atas adalah antara 302,6 VHN sampai 312,1 VHN dan pada bagian bawah antara 302,7 VHN sampai 310,2 VHN. Dengan tingkat keyakinan 95\%

Kemudian dilakukan pengujian dan pengukuran seterusnya sampai semua cincin torak selesai dilakukan pengujian dan pengukurannya. Hasilnya seperti tabel dibawah ini.

Table 1. Tabel hasil pengolahan data statistic 


\begin{tabular}{|c|c|c|c|c|c|c|c|c|c|c|}
\hline \multirow[t]{2}{*}{ No } & \multirow{2}{*}{$\begin{array}{c}\text { Jarak } \\
(\mathbf{k m})\end{array}$} & \multirow{2}{*}{$\begin{array}{c}\text { Jenis } \\
\text { CT }\end{array}$} & \multicolumn{2}{|c|}{$\begin{array}{l}\text { Kekerasan rata- } \\
\text { rata (VHN) }\end{array}$} & \multicolumn{2}{|c|}{ Standar deviasi } & \multicolumn{2}{|c|}{$\begin{array}{l}\text { Standar deviasi } \\
\text { rata-rata }\end{array}$} & \multicolumn{2}{|c|}{$\begin{array}{c}\text { Interval penduga rata-rata } \\
\text { kekerasan }\end{array}$} \\
\hline & & & Atas & Bawah & Atas & Bawah & Atas & Bawah & Atas & Bawah \\
\hline 1 & \multirow{3}{*}{0} & CTK I & 307,4 & 306,4 & 3,84 & 3,04 & 1,71 & 1,35 & $302,6-312,1$ & $302,7-310,2$ \\
\hline 2 & & $\begin{array}{l}\text { CTK } \\
\text { II }\end{array}$ & 417,6 & 423,8 & 4,39 & 5,63 & 1,96 & 2,51 & $412,15-423,04$ & $416,83-430,76$ \\
\hline 3 & & СТРP & 737 & 735 & 3,80 & 3,16 & 1,69 & 1,41 & $732,30-741,69$ & 731,08-738,91 \\
\hline 4 & \multirow{3}{*}{400} & CTK I & 364,2 & 344,6 & 4,14 & 6,22 & 1,85 & 2,78 & $359,06-369,33$ & $336,88-352,31$ \\
\hline 5 & & $\begin{array}{l}\text { CTK } \\
\text { II }\end{array}$ & 357 & 338,4 & 5,19 & 5,45 & 2,32 & 2,43 & $350,55-363,44$ & $331,65-345,14$ \\
\hline 6 & & СТPP & 723 & 735,2 & 6,67 & 5,06 & 2,98 & 2,26 & $714,72-731,27$ & $728,92-743,47$ \\
\hline 7 & \multirow{3}{*}{800} & CTK I & 374,6 & 352,6 & 5,59 & 3,64 & 2,49 & 1,62 & $367,68-381,51$ & $348,10-357,09$ \\
\hline 8 & & $\begin{array}{l}\text { CTK } \\
\text { II }\end{array}$ & 357 & 358,4 & 4 & 4,1 & 1,78 & 1,83 & $352,05-361,94$ & $353,31-363,48$ \\
\hline 9 & & СТРP & 751,2 & 751 & 5,54 & 6,51 & 2,47 & 2,91 & $744,34-758,08$ & $742,92-759,07$ \\
\hline 10 & \multirow{3}{*}{20.000} & CTK I & 398,2 & 385,8 & 2,58 & 3,03 & 1,15 & 1,35 & $395,1-401,39$ & $382,05-389,54$ \\
\hline 11 & & $\begin{array}{l}\text { CTK } \\
\text { II }\end{array}$ & 396,4 & 387 & 3,78 & 3,80 & 1,69 & 1,70 & $391,70-401,09$ & $382,28-391,71$ \\
\hline 12 & & СТРP & 786,2 & 792 & 2,94 & 4,30 & 1,31 & 1,92 & $782,56-789,83$ & $786,67-797,32$ \\
\hline 13 & \multirow{3}{*}{40.000} & CTK I & 424,8 & 447,4 & 4,96 & 3,64 & 2,21 & 1,62 & $418,66-430,93$ & $442,90-451,89$ \\
\hline 14 & & $\begin{array}{l}\text { CTK } \\
\text { II }\end{array}$ & 399,6 & 403 & 5,50 & 3,93 & 2,45 & 1,75 & $392,79-406,40$ & $398,14-407,85$ \\
\hline 15 & & СТРP & 799,8 & 797,6 & 6,30 & 3,04 & 2,81 & 1,35 & 791,99-807,60 & 793,85-801,34 \\
\hline
\end{tabular}

Cincin torak kompresi bekerja pada temperature $380^{\circ} \mathrm{C}$, sehingga tidak terjadi perubahan mikro struktur. Cincin torak kompresi mendapat panas dari gas pembakaran diruang bakar. Gas pembakaran dalam ruang bakar berupa campuran antara bahan bakar dan udara. Bahan bakar yang digunakan adalah bensin yang mengandung unsur karbon. Didalam ruang bakar terjadi pembakaran bahan bakar dengan udara yang salah satunya menghasilkan karbon. Pada waktu pembakaran terjadi ledakan pembakaran yang berguna untuk menggerakkan torak. Pada waktu terjadi ledakan karbon bergerak menumbuk cincin torak dengan kecepatan tinggi. Karena adanya panas ikatan atom pada cincin torak akan menjadi renggang dan lemah, sehingga memungkinkan karbon untuk berdifusi ke dalam cincin torak tersebut. Hal ini juga didukung atom karbon lebih kecil dari atom besi (Fe) sehingga atom karbon lebih mudah berdifusi ke dalam atom cincin torak tersebut. Dengan semakin banyaknya jarak tempuh maka penetrasi karbon kedalam cincin torak akan semakin besar, sehingga kekerasan akan semakin meingkat. Pada jarak $0 \mathrm{~km}$ (baru) mempunyai kekerasan yang rendah karena belum terjadi difusi karbon.

Jarak tempuh yang digunakan ada 5 buah, hal ini dimaksudkan untuk mengetahui sejauh mana perbedaan kekerasan yang ditimbulkan pada cincin torak dengan jarak tempuh yang berbedabeda.

A. Cincin torak kompresi I

Dari hasil Analisa hubungan kekerasan dengan jarak tempuh diperoleh, kekerasan cincin torak kompresi I mengalami peningkatan kekerasan. Laju peningkatan kekerasan ini cukup besar. Cincin torak kompresi I ini yang paling besar menahan tekanan gas pembakaran karena berhubungan dengan gas pembakaran. Panas hasil pembakaran yang diterima cincin torak ini juga cukup tinggi. Proses difusi terjadi pada cincin torak kompresi I, hal ini menyebabkan terjadinya peningkatan kekerasan cincin torak ini.

B. Cincin torak kompresi II

Dari hasil analisa hubungan kekerasan jarak tempuh juga diperoleh peningkatan kekerasan cincin torak kompresi II. Peningkatan kekerasan yang terjadi lebih lambat jika dibandingkan dengan cincin torak 
kompresi I. Tekanan gas pembakaran dan panas yang diterima cincin torak kompresi II semakin kecil. Panas hasil pembakaran sebagian besar telah disalurkan ke dinding silinder oleh cincin torak kompresi I. Begitu juga tekanan gas pembakaran yang diperoleh cincin torak ini telah ditahan oleh cincin torak kompresi I (hanya memperoleh tekanan gas pembakaran sisa). Hal menyebabkan difusi yang terjadi lebih lambat dari cincin torak kompresi I, karena penetrasi karbon kedalam cincin torak sedikit.

C. Cincin torak pengatur pelumasan

Dari hasil analisa hubungan kekerasan dengan jarak tempuh diperoleh bahwa kekerasan cincin torak pengatur pelumasan mengalami peningkatan kekerasan, walaupun peningkatan kekerasan ini tidak terlalu besar (lebih rendah dari cincin torak kompresi I). Peningkatan kekerasan cincin torak pengatur pelumasan cukup kecil atau kekerasan naik sedikit saja. Hal ini disebabkan karena cincin torak pengatur pelumasan ini beroperasi pada suhu yang rendah (sama dengan suhu pelumas) dan cincin torak ini tidak banyak dipengaruhi oleh gas pembakaran didalam ruang bakar. Tekanan yang diperoleh oleh cincin torak pengatur pelumasan juga sangat kecil sekali.

\section{KESIMPULAN}

Dari hasil penelitian dan pembahasan yang telah dilakukan dapat diambil kesimpulan sebagai berikut :

1. Kekerasan cincin torak mengalami perubahan kekerasan (peningkatan) setelah pemakain yang disebabkan oleh adanya difusi karbon ke dalam cincin torak.

2. Persentase peningkatan kekerasan cincin torak kompresi I sebesar 0,26 cincin torak kompresi II sebesar 0,051, cincin torak pengatur pelumasan sebesar 0,072.

3. Jarak tempuh mempengaruhi perubahan kekerasan cincin torak.

\section{DAFTAR PUSTAKA}

Aris Munandar, W., 2002, "Motor Bakar Torak”, Edisi Lima, Penerbit ITB, Bandung.

Daryanto. 2003. Dasar-dasar teknik mesin. Bumi Aksara. Jakarta.

Dasar-Dasar Sepeda Motor. Indonesia: Yamaha Motor CO.LTD

Drs. Daryanto. 2011. Prinsip Dasar, Mesin Otomotif, Bandung.

Hasan, Iqbal. 2006. Analisis Data Penelitian dengan Statistik. Jakarta:

https://uunuublog.wordpress.com/2017/10/ 04/menghitung-standar-deviasi/

https://id.scribd.com/doc/115762597/Lapo ran-Uji-Kekerasan.

https://www.academia.edu/37523255/TOR AK_BLOK_SILINDER_DAN_PO ROS_ENGKOL_PISTON_TORA $\mathrm{K}$

https://id.scribd.com/doc/50186047/Metod e-Pengujian-Kekerasan-Makalah- 